\title{
Heterogeneity of mechanisms in exercise induced asthma
}

The development of airflow limitation that occurs in $70-80 \%$ of people with asthma several minutes after vigorous exercise is known as exercise induced asthma. In most asthmatic patients the airflow obstruction is reversed spontaneously within 60 minutes. There are, however, asthmatic individuals who have more prolonged airways obstruction and who require bronchodilator treatment to recover pre-exercise lung function. After exercise $40-50 \%$ of asthmatic individuals with exercise induced asthma will be less responsive to an identical exercise task performed within one hour. ${ }^{2}$ This is known as the refractory period. ${ }^{3}$ In some patients, particularly children, exercise induced asthma will be followed three to nine hours later by a further decrease in lung function, termed the late reaction. $^{4-7}$ In most asthmatic subjects with exercise induced asthma the administration of sodium cromoglycate or a $\beta_{2}$ sympathomimetic aerosol immediately before exercise will prevent the development of the initial ${ }^{8}$ and late phase asthmatic reactions. ${ }^{6}$

Although exercise induced asthma has been recognised for centuries there is still considerable debate about its pathogenesis. Some of the controversy may relate to the attempt to seek a single mechanism to explain a condition in which several mechanisms may exist. The recognition that exercise induced asthma is only sometimes followed by a refractory period, that the inhibitory effect of sodium cromoglycate and the anticholinergic agent ipratropium bromide is not universal, and that bronchoactive mediators cannot be detected in the circulation of all patients with the condition suggests that there may be several different mechanisms causing exercise induced asthma.

\section{Respiratory heat loss as the initiating stimulus for exercise induced asthma}

When air of temperate conditions is inspired during quiet breathing, heat and water are transferred from

Address for reprint requests: Dr TH Lee, Department of Medicine, Guy's Hospital, London SE1 9RT.

Accepted 10 December 1984 the bronchial mucosa of the upper airways to the incoming air, so that the air is warmed to body temperature and fully saturated with water. During this process, there is convective and evaporative cooling of the airways. Although on expiration some of the vaporised water condenses back to the airways and some heat is returned to the mucosa, the net effect of these exchanges results in a loss of both heat and water from the respiratory tract. During breathing in temperate climates about $80 \%$ of the heat loss is caused by the vaporisation of water, ${ }^{9}$ but as the temperature of the inspired air is decreased the contribution from convective cooling becomes greater. Because cold air is always dry the magnitude of the respiratory heat loss will be greater when subjects breath air at subfreezing temperatures than when they breathe air of temperate conditions. As expired air is almost fully saturated with water, respiratory water loss during ventilation will depend on the concentration of water in the inspired air and on the temperature of the expired air.

The importance of respiratory heat loss and subsequent airway cooling to the pathogenesis of exercise induced asthma was recognised by Chen and Horton, ${ }^{10}$ who showed that exercise induced asthma could be prevented by inhaling warm, humid air during exercise. Evidence to support the theory that airway cooling was the stimulus for exercise induced asthma came from several observations. It was shown that the inhalation of cold, dry air during exercise caused a greater reduction in $\mathrm{FEV}_{1}$ and specific airway conductance than did the inhalation of ambient or hot, dry air. ${ }^{11} 12$ The magnitude of the airway response was shown to be directly related to the calculated heat loss in bringing the inspired air to alveolar conditions ${ }^{10}$ and to the measured respiratory heat loss. ${ }^{13}$ Quantitative expressions were developed that suggested that respiratory heat loss was directly proportional to the minute ventilation and it was reasoned that, since the level of ventilation was an important determinant of the quantity of heat transferred from the mucosa, it should be possible to reproduce the extent of the airflow obstruction associated with exercise by carrying out voluntary hyperventilation. ${ }^{13}$ Hyperventilation, in contrast to exercise, decreases the end tidal carbon 
dioxide. Thus if hyperventilation is to be used as an experimental model for exercise induced asthma, additional carbon dioxide must be supplied to the inspired air during the hyperventilation procedure to maintain isocapnia. In patients subjected to isocapnic hyperventilation with fully saturated air at body temperature asthma did not develop. If, however, the water content and temperature of the inspired air were reduced, thereby increasing the calculated respiratory heat loss, bronchoconstriction occurred..$^{13}$ The documentation of a reduction in retrotracheal, airway, and expired air temperatures during hyperventilation with subfreezing air provided direct evidence for airway cooling. ${ }^{13-15}$ As a result of these studies it was generally accepted that the only stimulus for exercise induced asthma was cooling of the intrathoracic airways brought about by the conditioning of the inspired air to full saturation at $37^{\circ} \mathrm{C}^{10^{-14}}$

\section{Respiratory water loss as the initiating stimulus for exercise induced asthma}

The possibility that respiratory water loss may act as a stimulus for exercise induced asthma through its direct effect in drying the airways, rather than via its effect in augmenting respiratory heat loss, has been discussed only recently. ${ }^{16}{ }^{17}$ It has been suggested that an increased rate of respiratory water loss, caused by the hyperpnoea of exertion, induces a transient hyperosmolarity of the respiratory epithelium ${ }^{16}{ }^{17}$ and that this is an even more potent stimulus for bronchoconstriction than respiratory heat loss. ${ }^{18-21}$ This reinterpretation of the initiating stimulus for exercise induced asthma resulted from a detailed analysis of data from the early studies on the role of respiratory heat loss in exercise induced asthma, from the results of a series of experiments which indicated that the condition could occur when respiratory heat loss was negligible and under conditions that induced only small changes in retrotracheal temperatures, ${ }^{1618-20}$ and from the knowledge that a hyperosomolar stimulus to the airways of asthmatic individuals leads to bronchoconstriction. ${ }^{22} 23$

Analysis of data from the study of Deal et $a l^{13}$ showed that, even when the amount of heat lost from the airways during exercise was reduced from $1.68 \mathrm{kcal}(7.03 \mathrm{~kJ}) / \mathrm{min}$ to $0.88 \mathrm{kcal}(3.68 \mathrm{~kJ}) / \mathrm{min}$ by increasing the inspired air temperature from $24^{\circ}$ to $80^{\circ} \mathrm{C}$, the severity of asthma induced by the challenges was essentially the same. Furthermore, when the temperature of the inspired air was $80^{\circ} \mathrm{C}$, the expired air temperature was $37.1^{\circ} \mathrm{C}$, suggesting that the temperature of the airway mucosa was not abnormally low. It is difficult to believe that cooling of the airway mucosa occurred during exercise when the temperature of the expired air was higher than the value normally recorded at rest. The original studies that evaluated the relationship between respiratory heat loss and exercise induced asthma did not make recordings of airway temperature when hot dry air was inspired; possibly the conclusion would have been different had these measurements been included. ${ }^{14} \mathrm{Hahn}$ et al have recently reported a study in which they conditioned the air inspired by 10 asthmatic subjects during different exercise tasks to give it the same water content while changing the temperature and vice versa. ${ }^{19}$ The air was conditioned to a temperature of $9^{\circ}$ or $35^{\circ} \mathrm{C}$ with an inspired water content of $9 \mathrm{mg}$ water/litre or 29 $\mathrm{mg}$ water/l. The airway responses of the asthmatic subjects to exercise were not significantly different even though the temperature of the inspired air varied by $26^{\circ} \mathrm{C}$ and the amount of heat required to bring the inspired air to alveolar conditions was significantly greater for cooler air. Sheppard et al subjected 12 asthmatic patients to hyperventilation breathing dry air at three different temperatures $\left(-5^{\circ}, 22^{\circ}\right.$, and $\left.37^{\circ} \mathrm{C}\right) .^{20}$ The respiratory heat loss was calculated and the minute ventilation required to produce a $100 \%$ increase in specific airways resistance was documented. Despite significant differences in respiratory heat loss, the minute ventilation required to elicit the same increase in airways resistance was not significantly different under the three conditions. These observations indicate that the airway response in exercise induced asthma will be similar if the respiratory water loss remains the same, even though the respiratory heat loss may vary.

Although further studies are required to confirm that there is a change in the osmolarity of the epithelial fluid lining the airway mucosa during exercise induced asthma, there is evidence that increasing evaporative water loss by breathing through the mouth rather than the nose induces substantial increases in the osmolarity of respiratory tract secretions. ${ }^{24-26}$ That hyperosmolarity of the respiratory epithelium is a stimulus for bronchoconstriction has been documented by several investigators. ${ }^{22}{ }^{23}$ Anderson et al showed a direct relationship between the extent of the osmotic stimulus to the airways and its potency in producing airflow obstruction. They further showed that the bronchoconstriction resulting from the inhalation of ultrasonically nebulised hypertonic and hypotonic saline solutions could be inhibited by the prior administration of sodium cromoglycate..$^{22}$ Hypertonic and hypotonic solutions of sodium chloride differ from isotonic saline not only in osmolarity but also in ion content. It was therefore important to separate these 
two factors before it could be concluded that alterations in airway fluid osmolarity could be a stimulus to bronchoconstriction. Eschenbacher et al showed that the inhalation of an aerosol of iso-osmolar dextrose solution by asthmatic subjects did not cause airflow obstruction, whereas an aerosol of hyperosmolar dextrose solution elicited asthma, thus confirming the suggestion that hyperosmolarity is a stimulus to bronchoconstriction. ${ }^{23}$ If respiratory water loss is a major initiating stimulus for exercise induced asthma, it is understandable that the inhalation of dry air over a wide range of temperatures during exercise or hyperventilation will result in the development of similar degrees of airflow obstruction. ${ }^{1319} 20$ Furthermore, the capacity of humidified air to reduce exercise induced asthma is related to its ability to modify respiratory water loss per se, rather than to its effect in diminishing respiratory heat loss. ${ }^{1217}$

\section{Interactions between different initiating stimuli}

It is certainly possible that in selected circumstances airway cooling and drying may operate together to initiate exercise induced asthma. For example, when air of subfreezing temperature is inhaled both heat and water loss will occur, resulting in a change in the osmolarity of the epithelial fluid and cooling of the mucosa. This may explain why the enhancement of exercise induced asthma with cold air occurred in the patients studied by Deal et al. ${ }^{13}$ When the same subjects inspired dry air at temperatures varying from $24^{\circ}$ to $80^{\circ} \mathrm{C}$ the airway response was similar because the rate of water loss was the same. Patients with asthma probably differ in their sensitivity to airway cooling or changes in osmolarity since enhancement of exercise induced asthma by inhalation of cold, dry air is not universal, and not all patients develop exercise induced asthma when they exercise while breathing hot, dry air.

\section{Sustaining events}

The mechanisms by which an osmotic stimulus or airway cooling induces asthma are unknown but substances capable of inducing bronchial smooth muscle contraction may be released from mediator cells in the bronchial mucosa in response to these stimuli. This is supported by the demonstration that a hyperosmolar or a cold stimulus can lead to mast cell activation and mediator release in vitro and in vivo. ${ }^{27-24}$ The knowledge that pharmacological agents that prevent mediator release inhibit exercise induced asthma $\mathrm{m}^{8}$ and the detection of mediators of hypersensitivity in the circulation of many asthmatic subjects during exercise induced asthma constitute further in vivo evidence to support the role of mediators in eliciting the airflow obstruction.

\section{Evidence for mediator release}

\section{NEUTROPHIL CHEMOTACTIC FACTOR}

A neutrophil chemotactic factor of high molecular weight is detectable in the circulation of $75 \%$ of asthmatic subjects during exercise induced asthma. ${ }^{3031}$ Its appearance accompanies the development of airflow obstruction and can be prevented by the administration of sodium cromoglycate before exercise. ${ }^{3032}$ The release of this mediator is not due to the bronchoconstriction itself since histamine and methacholine inhalation challenges, which elicit the same degree of airflow obstruction as exercise, do not release this factor. ${ }^{30} 32$ The elaboration of neutrophil chemotactic factor is not a consequence of exercise per se, because normal individuals who perform the same exercise task as the asthmatic subjects do not release this chemotactic factor. ${ }^{30} \mathrm{~A}$ treadmill exercise undertaken by asthmatic patients while breathing warm, humid air does not release this mediator, whereas the same exercise undertaken by the same patients while inspiring cold, dry air produces detectable circulating neutrophil chemotactic factor. ${ }^{33}$ The appearance of this mediator is related to the severity of exercise induced asthma in individual patients and is independent of atopic status. ${ }^{34}$ Of particular relevance is the fact that neutrophil chemotactic factor release has also been documented after osmotic challenge to the airways in vivo. ${ }^{29}$ It has not been detected after isocapnic hyperventilation with cold air. ${ }^{35-37}$ It is possible, however, that this form of challenge may have released neutrophil chemotactic factor locally in the bronchial mucosa and that its appearance in the peripheral circulation was prevented or delayed because of changes in the local bronchial circulation as a result of the fall in airway temperature. It is also possible that exercise may facilitate the detection of neutrophil chemotactic factor in the circulation by increasing cardiac output and changing the perfusion of the lungs-haemodynamic changes that do not occur to the same extent during isocapnic hyperventilation. ${ }^{38}$

The suggestion that pharmacological mediators may be important in the pathogenesis of exercise induced asthma, at least in some patients, is supported by the recognition of a late phase asthmatic response that may occur three to nine hours after exercise and is prevented by pretreatment with sodium cromoglycate. ${ }^{4-7}$ The propensity to develop late phase reactions after exercise is not determined 
by differences in severity of disease or by the extent of baseline airway reactivity in asthmatic subjects. ${ }^{39}$ In susceptible individuals there is a correlation between the severity of the early reactions and the magnitude of the late phase responses. Spontaneous recovery from the early reaction is significantly slower and less complete in those subjects who develop a subsequent late reaction than it is in individuals who develop an early response only. ${ }^{39}$ Exercise induced late phase reactions are also accompanied by the release of neutrophil chemotactic factor, as are allergen induced late responses. ${ }^{40}$ These findings are consistent with the view that factors associated with the early reaction in exercise induced asthma sustain the initial airways obstruction and in turn lead to a second release of mediators and the development of a late phase reaction. Nevertheless, only a minority of asthmatic individuals have late reactions after exercise and neutrophil chemotactic factor release cannot be detected in $25 \%$ of asthmatic patients during exercise induced asthma ${ }^{31}$-observations supporting the hypothesis of several underlying mechanisms causing the condition.

Mediators released in exercise induced asthma may have a more generalised proinflammatory effect by activating circulating neutrophils. Asthmatic subjects with exercise induced asthma have a time dependent increase in the expression of neutrophil complement (CR1) receptors for up to 60 minutes after exercise. ${ }^{41}$ The enhancement of CR1 receptors, as evidence of neutrophil activation, is preceded by an increase in circulating neutrophil chemotactic factor and a reduction in FEV . These changes in neutrophil membrane receptors are not observed in asthmatic subjects who do not have exercise induced asthma after similar treadmill exercise. Furthermore, the prior administration of sodium cromoglycate to asthmatic patients not only inhibits the asthma but also prevents the release of mediators and the enhancement of CR1 receptors. When neutrophils from normal donors are incubated with partially purified neutrophil chemotactic factor in vitro, there is a dose related enhancement of CR1 receptors. ${ }^{41}$ These findings suggest that, as a result of chemotactic factor release, the inflammatory potential of circulating leucocytes may be augmented after exercise induced asthma and this may contribute to bronchial inflammation. Airway inflammation may disrupt epithelial integrity, increase mucosal permeability, and contribute to the smooth muscle hyperresponsiveness that is characteristic of bronchial asthma. This sequence of events may explain the enhanced airway response to methacholine and histamine inhalation induced by a previous challenge with aerosolised water. ${ }^{42}$
HISTAMINE

Several studies s24-45 $^{32}$ have shown increases in plasma histamine concentration of $7-14 \mathrm{pmol} / \mathrm{ml}$ during an exercise induced attack of asthma. In some studies a significant increase in plasma histamine concentration was not found in all subjects and in $40-50 \%$ of patients with exercise induced asthma the changes were similar to those observed in non-asthmatic subjects. ${ }^{43-45}$ The increases in plasma histamine during the asthmatic attack could be inhibited with inhaled sodium cromoglycate and terbutaline given before exercise. ${ }^{3243}$ Anderson has proposed that small increases in plasma histamine concentrations may reflect much larger increases in the lung because the bronchial circulation is only $1-2 \%$ of the cardiac output and there is rapid metabolism of histamine in the peripheral circulation. ${ }^{2}$ Other workers have suggested that detectable increases in plasma histamine concentrations are due to spontaneous release from "leaky" basophils, which increase in number after exercise. ${ }^{44-48}$ It seems unlikely, however, that basophils are the only cause of the histaminaemia detected in exercise induced asthma for several reasons. Spontaneous histamine release from basophils of asthmatic subjects decreases after exercise; subjects with exercise induced asthma (EIA +$)$ have a postexercise basophilia similar to that of asthmatic patients without exercise induced asthma (EIA -$),{ }^{36}$ but only EIA + individuals release histamine; ${ }^{34}$ and an increase in plasma histamine occurs after hyperventilation induced asthma in the absence of basophilia. ${ }^{37}$ Studies which have shown a significant correlation between whole blood or plasma histamine concentrations and the level of postexercise basophilia have all been unable to detect significant increases in the concentrations of this mediator in exercise induced asthma or to distinguish between asthmatic individuals and normal controls. The basophil is an important repository for histamine and the spontaneous release of this mediator from basophils contributes to the resting concentrations of plasma histamine. It is thus understandable that in postexercise basophilia the plasma concentration of histamine will be increased even in patients who do not release histamine from pulmonary mast cells. The inability to detect significant increases in plasma histamine in exercise induced asthma in some studies may have been related to difficulties in sample handling, to sampling of venous blood, ${ }^{48}$ to different assay techniques for measuring plasma histamine,$^{49}$ and to the influence of baseline airway reactivity on the detection of mediators in the peripheral circulation. ${ }^{5051}$ These explanations probably do not account for all of the discrepant findings and it is likely that release of histamine just does not 
occur during exercise induced asthma in some asthmatic subjects. ${ }^{43} 4$

\section{Refractory period}

The refractory period is defined as the period during which a repeated exercise under identical conditions induces less than $50 \%$ of the initial asthmatic response. With this definition $40-50 \%$ of asthmatic subjects whose lung function returns to within $15 \%$ of pre-exercise levels will be refractory to exercise induced asthma when a second exercise is undertaken within two hours..$^{52}$ The cause of refractoriness is not known. It has been suggested that the refractory period may be evidence of mediator release and reflect the time needed for replenishment of mediator stores. ${ }^{3}$ Its duration is, however, unrelated to the severity of exercise induced asthma and $50 \%$ of asthmatic patients made refractory to such an attack by repeated running still developed bronchoconstriction to inhaled allergen. ${ }^{53}$ Furthermore, $80 \%$ of a group of asthmatic subjects could be rendered refractory to further exercise induced asthma by an initial exercise, performed while breathing warm, humid air, after which there was no asthma. ${ }^{54}$ These findings suggest that there are probably other mechanisms besides mediator depletion contributing to the presence of a refractory period in exercise induced asthma and these remain unexplained. It has been suggested that the development of a refractory period is related to the release of endogenous catecholamines that protect the airways from a subsequent bronchoconstrictor stimulus. ${ }^{55}$ This seems unlikely for two reasons. Firstly, the increased circulating catecholamine concentrations return to baseline values shortly after exercise $^{56}$ but the refractory period may last up to four hours. ${ }^{3}$ Secondly, voluntary hyperventilation does not release catecholamines ${ }^{56}$ but does render asthmatic subjects refractory to the development of exercise induced asthma. Wilson $e^{2} a^{57}$ showed that $42 \%$ of asthmatic patients have no refractory period after hyperventilation induced asthma, whereas the remaining patients had a considerable refractory period when hyperventilation was repeated within 40 minutes. In subjects who were not refractory cholinergic blockade prevented the development of hyperventilation induced bronchoconstriction, suggesting that vagal reflexes may participate in the pathogenesis of their airflow obstruction. In contrast, ipratropium bromide was not effective in inhibiting hyperventilation induced asthma in the group of patients who showed refractoriness to a subsequent hyperventilation challenge. Thus isocapnic hyperventilation, which is thought to produce bronchoconstriction through mechanisms similar to those at work in exercise induced asthma, also shows evidence of dif- ferent pathogenetic mechanisms.

\section{Conclusions}

Since exercise induced asthma refers to a clinical association, defined by physiological criteria with no comment on pathogenesis, it is not surprising that there may be different underlying mechanisms. Perhaps future studies should be directed towards identifying subpopulations of asthmatic individuals in whom a specific stimulus, such as respiratory water loss or airway cooling or both, with or without the participation of mediator release, contributes to exercise induced asthma. This approach may be more suitable than lengthy debate about which mechanism is more important. The recognition of the potential for different mechanisms causing exercise induced asthma and an appreciation of the interactions between various stimuli may lead to a better understanding of airway hyperreactivity.

TAK H LEE

Department of Thoracic Medicine Guy's Hospital London SE1 9RT

SANDRA D ANDERSON Department of Thoracic Medicine Royal Prince Alfred Hospital Camperdown 2050, New South Wales Australia

\section{References}

1 Schoeffel RE, Anderson SD, Gillam I, Lindsay DA. Multiple exercise and histamine challenges in asthmatic patients. Thorax 1980;35:164-70.

2 Anderson SD. Recent advances in the understanding of exercise-induced asthma. Eur J Respir 1983;64, suppl 128:225-36.

3 Edmunds AT, Tooley M, Godfrey S. The refractory period after exercise-induced asthma: its duration and relation to severity of exercise. Am Rev Respir Dis 1978; 117:247-54.

4 Lee TH, Nagakura T, Papageorgiou N, Iikura Y, Kay AB. Exercise-induced late asthmatic reactions with neutrophil chemotactic activity. $N$ Engl J Med 1983;308: 1502-5.

5 Bierman CW, Spiro SG. Characterization of the late response in exercise-induced asthma. J Allergy Clin Immunol 1984;74:701-6.

6 Feldman CH, Fox J, Kraut E, Feldman BR, Davis WJ. Exercise-induced asthma (EIA): treatment for early and late responses. Am Rev Respir Dis 1982;125:195 (abstract).

7 Horn CR, Jones RM, Lee D, Brennan SR. Late response in exercise-induced asthma. Clin Allergy 1984; 14:307-9.

8 Anderson SD, Seale JP, Ferris L, Schoeffel RE, Lindsay DA. An evaluation of pharmacotherapy for 
exercise-induced asthma. $J$ Allergy Clin Immunol 1979;64:612-24.

9 Otis AB. Quantitative relationships in steady-state gas exchange. In: Fenn WO, Rahn $\mathrm{H}$, eds. Handbook of physiology. Section 3: Respiration. Washington DC: American Physiological Society, 1964:697.

10 Chen WY, Horton DJ. Heat and water loss from the airways and exercise-induced asthma. Respiration $1977 ; 34: 305-13$

11 Strauss RH, McFadden ER, Ingram RH, Jaeger JJ. Enhancement of exercise-induced asthma by cold air. N Engl J Med 1977;297:743-7.

12 Strauss RH, McFadden ER, Ingram RH, Deal EC, Jaeger JJ, Stearns D. Influence of heat and humidity on the airway obstruction induced by exercise in asthma. $J$ Clin Invest 1978;61:433-40.

13 Deal EC, McFadden ER, Ingram RH, Strauss RH, Jaeger JJ. Role of respiratory heat exchange in production of exercise-induced asthma. J Appl Physiol 1979; 46: 467-75.

14 Deal EC, McFadden ER, Ingram RH, Jaeger JJ. Esophageal temperature during exercise in asthmatic and non-asthmatic subjects. J Appl Physiol 1979; 46:484-90.

15 McFadden ER, Denison DM, Waller JF, Assoufi B, Peacock A, Sopwith T. Direct recordings of the temperatures in the tracheobronchial tree in normal man. J Clin Invest 1982; 69:700-5.

16 Anderson SD, Schoeffel RE, Follet R, Perry CP, Daviskas E, Kendall M. Sensitivity to heat and water loss at rest and during exercise in asthmatic patients. Eur J Respir Dis 1982;63:459-71.

17 Anderson SD. Is there a unifying hypothesis for exercise-induced asthma? J Allergy Clin Immunol 1984; 73:660-5.

18 Anderson SD, Schoeffel RE, Black JL, Daviskas E. Airway cooling as the stimulus to exercise-induced asthma: a re-evaluation. Eur J Respir Dis (in press).

19 Hahn A, Anderson SD, Morton AR, Black JL, Fitch $K$. A reinterpretation of the effect of temperature and water content of the inspired air in exercise-induced asthma. Am Rev Respir Dis 1984;130:575-9.

20 Sheppard D, Eschenbacher WL. Respiratory water loss as a stimulus to exercise-induced bronchoconstriction. J Allergy Clin Immunol 1984;73:640-2.

21 Aitken ML, Marini JJ. Effect of heat delivery and extraction on airway conductance in normal and asthmatic subjects. Am Rev Respir Dis 1985; 131:357-61.

22 Anderson SD, Schoeffel RE, Finney M. Evaluation of ultrasonically nebulised solutions as a provocation in patients with asthma. Thorax 1983;38:284-91.

23 Eschenbacher WL, Boushey HA, Sheppard D. Alterations in osmolarity of inhaled aerosols cause bronchoconstriction and cough but absence of a permeant anion causes cough alone. Am Rev Respir Dis 1984;129:211-5.

24 Potter JI, Leroy WM, Spector S, Lemm J. Studies on pulmonary secretions. Am Rev Respir Dis 1967;96:83-7.

25 Man SFP, Adams GK III, Proctor DF. Effects of temperature, relative humidity and mode of breathing on canine airway secretions. J Appl Physiol 1979; 46: 205-10.

26 Boucher RC, Stutts MJ, Bromberg PA, Gatzy JT. Regional differences in airway surface liquid composition.
J Appl Physiol 1981;50:613-30.

27 Eggleston PA, Kagey-Sobotka A, Schleimer RP, Lichtenstein LM. Interaction between hyperosmolar and IgE mediated release from basophils and mast cells. Am Rev Respir Dis 1984;130:86-91.

28 Wasserman SI, Soter NA, Center DM, Austen KF. Cold urticaria. Recognition and characterisation of a neutrophil chemotactic factor, which appears in serum during experimental cold challenge. J Clin Invest 1977;60: 180-96.

29 Shaw R, Anderson SD, Durham S, et al. Mediators of hypersensitivity and fog induced asthma. Allergy 1985; 40:48-57.

30 Lee TH, Nagy L, Nagakura T, Walport MJ, Kay AB. Identification and partial characterization of an exercise-induced neutrophil chemotactic factor in bronchial asthma. J Clin Invest 1982; 69:889-99.

31 Lee TH, Nagakura T, Papageorgiou N, Cromwell O, Iikura Y, Kay AB. Mediators in exercise-induced asthma. J Allergy Clin Immunol 1984;23:634-9.

32 Lee TH, Brown MJ, Nagy L, Causon R, Walport MJ, Kay AB. Exercise-induced release of histamine and neutrophil chemotactic factor in atopic asthmatics. $J$ Allergy Clin Immunol 1982; 70:73-81.

33 Lee TH, Assouf BK, Kay AB. The link between exercise, respiratory heat exchange, and the mast cell in bronchial asthma. Lancet 1983; i:520-2.

34 Lee TH, Nagakura T, Cromwell O, Brown MJ, Causon R, Kay AB. Neutrophil chemotactic activity and histamine in atopic and non-atopic subjects after exercise-induced asthma. Am Rev Respir Dis 1984;129:409-12.

35 Deal EC, Wasserman SI, Soter NA, Ingram RH, McFadden ER. Evaluation of the role played by mediators of immediate hypersensitivity in exerciseinduced asthma. J Clin Invest 1980;65:659-65.

36 Nagakura T, Lee TH, Assoufi BK, Denison DM, Newman-Taylor AJ, Kay AB. Neutrophil chemotactic factor in exercise and hyperventilation induced asthma. Am Rev Respir Dis 1983;128:294-6.

37 Lee TH, Assoufi BK, Cromwell O, Kay AB. Exerciseinduced asthma and the mast cell. Lancet 1983;ii: 164-5.

38 Matalon S, Dahkoff N, Nesarajah MS, Klocke FJ, Fahri LE. Effects of hyperventilation on pulmonary blood flow and recirculation time of humans. J Appl Physiol 1982;82:1161-5.

39 Iikura Y, Inui H, Nagakura T, Lee TH. Factors predisposing to exercise-induced late asthmatic responses. $J$ Allergy Clin Immunol 1985;75:285-9.

40 Nagy L, Lee TH, Kay AB. Neutrophil chemotactic activity in antigen-induced late asthmatic reactions. $N$ Engl J Med 1982;306:497-501.

41 Papageorgiou N, Carroll M, Durham SR, Lee TH, Walsh GM, Kay AB. Complement receptor enhancement as evidence of neutrophil activation following exercise-induced asthma. Lancet 1983;ii:1220-3.

42 Black JL, Schoeffel RE, Anderson SD, Berend N Increased airway responsiveness to methacholine inhalation after ultrasonically nebulised water $\left(\mathrm{UNH}_{2} \mathrm{O}\right)$ challenge in patients with asthma. Am Rev Respir Dis 1984;129: A263 (abstract).

43 Anderson SD, Bye PTP, Schoeffel RE, Seale JP, Taylor KM, Ferris L. Arterial plasma histamine levels at rest, during and after exercise in patients with asthma: effects of terbutaline aerosol. Thorax 
1981;36:259-67.

44 Barnes PJ, Brown MJ. Venous plasma histamine in exercise-and hyperventilation-induced asthma in man. Clin Sci 1981;61:159-62.

45 Hartley JPR, Charles TJ, Monie RDH, et al. Arterial plasma histamine after exercise in normal individuals and in patients with exercise-induced asthma. Clin Sci 1981;61:151-7.

46 Morgan DJR, Moodley I, Phillips MJ, Davies RJ. Plasma histamine in asthmatic and control subjects following exercise: influence of circulating basophils and different assay techniques. Thorax 1983;38:771-7.

47 Howarth PH, Pao GJK, Church MK, Holgate ST. Exercise and isocapnic hyperventilation-induced bronchoconstriction in asthma: relevance of circulating basophils to measurements of plasma histamine. J Allergy Clin Immunol 1984; 73:391-9.

48 Harries MG, Burge PS, O'Brien I, Cromwell O, Pepys J. Blood histamine levels after exercise testing. Clin Allergy 1979;9:437-41.

49 Gleich GJ, Hall WM. Measurement of histamine: a quality control study. J Allergy Clin Immunol 1980;66:295-8.

50 McFadden ER, Soter NA, Ingram RH. Magnitude and site of airways response to exercise in asthmatics in relation to arterial histamine levels. J Allergy Clin Immunol 1980;66:472-7.

51 Howarth PH, Lee TH, Nagakura T, Durham SR, Kay AB, Holgate ST. Mediator release associated with clinical models of asthma. Thorax 1984;39:698-9 (abstract).

52 Anderson SD. Exercise-induced asthma: the state of the art. Chest (in press).

53 Weiler-Ravell D, Godfrey S. Do exercise and antigeninduced asthma utilize the same pathways? J Allergy Clin Immunol 1981;67:391-7.

54 Ben-Dov I, Bar-Yishay E, Godfrey S: Refractory period after exercise-induced asthma unexplained by respiratory heat loss. Am Rev Respir Dis 1982;125:530-4.

55 Stearns DR, McFadden ER, Breslin FJ, Ingram JR. Reanalysis of the refractory period in exertional asthma. J Appl Physiol 1981;50:503-8.

56 Barnes PJ, Brown MJ, Silverman M, Dollery CT. Circulating catecholamines in exercise- and hyperventilation-induced asthma. Thorax 1981;30:435-40.

57 Wilson NM, Barnes PJ, Vickers H, Silverman M. Hyperventilation-induced asthma: evidence for two mechanisms. Thorax 1982;37:657-62. 